\title{
EXPERIMENTAL PNEUMOCOCCUS LOBAR PNEUMONIA IN THE DOG
}

\author{
III. Pathogenesis \\ By OSWALD H. ROBERTSON, LOWELL T. COGGESHALL AND \\ EDWARD E. TERRELL \\ (From the Department of Medicine, University of Chicago, Chicago)
}

(Received for publication October 31, 1932)

The preceding paper (1) dealt with the pathology of the pulmonary lesions found in dogs dying from experimental pneumococcus pneumonia or killed after the disease had been well established. In the present communication observations on the successive changes leading to the development of the typical lesions are presented. Nineteen dogs, infected as previously described (2), were sacrificed at intervals of one to twentyfour hours. The details of dosage, observed changes during life, autopsy findings, etc., are shown in Table I.

\section{One hour lesion}

By the end of an hour well marked changes were found (Dogs 58 and 32, Table I). At the site of injection, the posterior lower edge of the right lower lobe, there was a small roughly circular slightly hemorrhagic area, 1.5 to $2.5 \mathrm{~cm}$. in diameter. This area was firmer than the surrounding lung tissue, and extended from the posterior to the inferior surface. The cut surface showed a mottled appearance, somewhat darker than normal lung tissue, and was dry. The area of involvement probably corresponds quite closely to the original distribution of the injected material, since an $\mathrm{x}$-ray of a normal lung into which $1 \mathrm{cc}$. of lipiodol had been injected into the same place showed a shadow of approximately analogous size. X-ray of the lesion is shown in Figure 1.

Microscopically, there was seen under low magnification an area of infiltration 3 to $4 \mathrm{~mm}$. in diameter with other smaller areas covering a zone $1 \mathrm{~cm}$. across. ${ }^{1}$ The infiltration, chiefly intra-alveolar in character, was most marked in the immediate vicinity of the main bronchus and its branches. It was rather irregular in distribution and consisted of starch, blood cells and edema fluid. In the center of this area the exudate was

1 The marked shrinkage which the tissues undergo in the process of embedding in paraffin would account for the difference between the fresh lesion and the microscopic slide. 


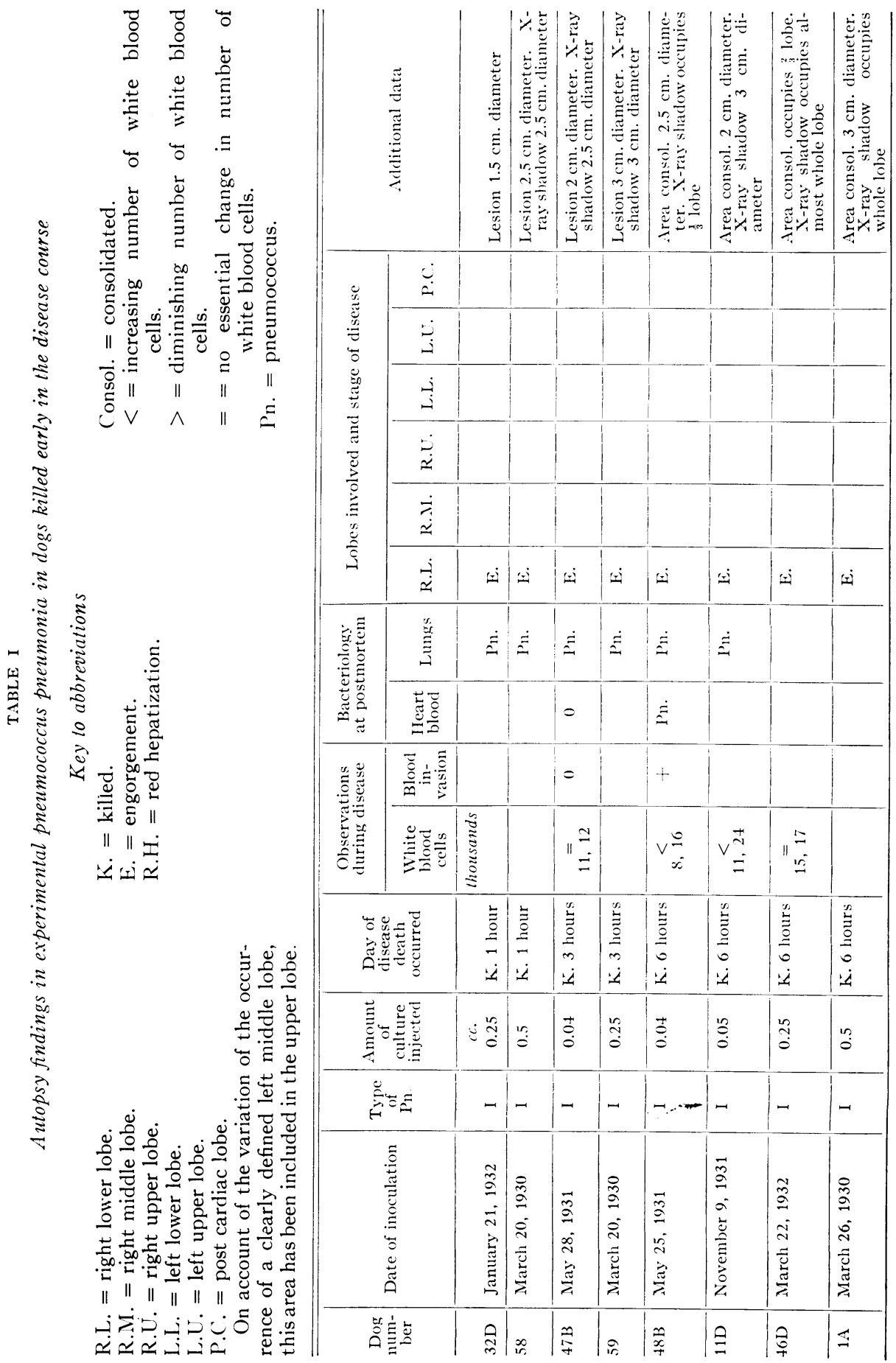


O. H. ROBERTSON, L. T. COGGESHALL AND E. E. TERRELL 469

\begin{tabular}{|c|c|c|c|c|c|c|c|c|c|c|c|c|c|}
\hline & 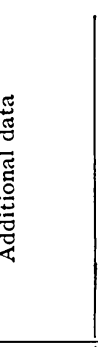 & 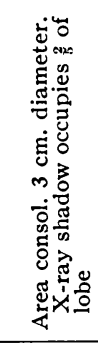 & 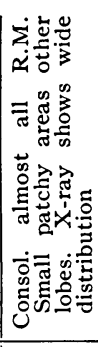 & 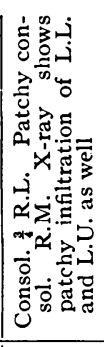 & 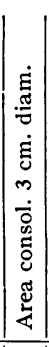 & 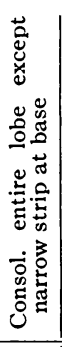 & 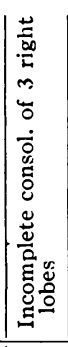 & 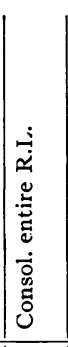 & 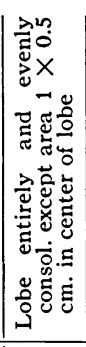 & 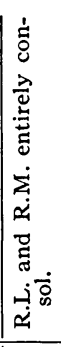 & 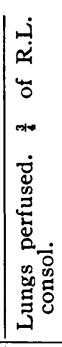 & 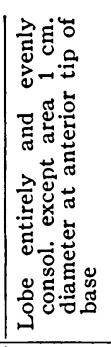 & \multirow{16}{*}{ 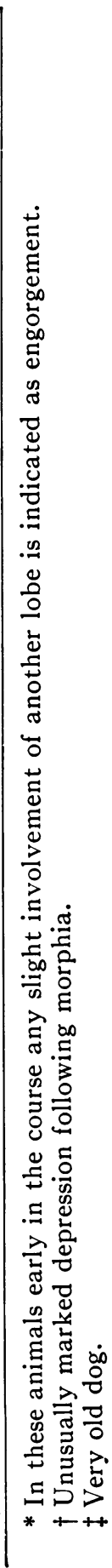 } \\
\hline \multirow{6}{*}{ 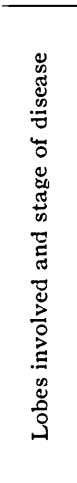 } & ن̈ & & $"$ & & & & & & & |匚 & & & \\
\hline & نُ & & & & & & & (19) & & વَ & a & & \\
\hline & نذّ & & |ri & & & & |x & & & & & & \\
\hline & $\stackrel{\dot{\leftrightarrow}}{\dot{q}}$ & & $\not \dot{x}$ & & & & 도 & & & & & & \\
\hline & $\underset{\dot{\Sigma}}{\dot{\varkappa}}$ & & 菂 & 藏 & & & ن & & & | & & & \\
\hline & $\stackrel{\dot{\leftrightarrow}}{\sim}$ & ف & 19 & 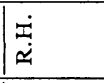 & (15) & | & 茨 & 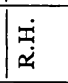 & 茫 & | & 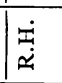 & $\mid$\begin{tabular}{l}
$\dot{1}$ \\
\multicolumn{2}{|c|}{}
\end{tabular} & \\
\hline \multirow{4}{*}{ 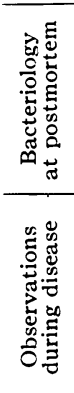 } & 点 & $\dot{\Xi}$ & $\dot{n}$ & $\dot{\Xi}$ & 家 & $\dot{\text { m }}$ & 㕵 & $\dot{\text { g }}$ & $\dot{\text { g }}$ & $\dot{\text { a }}$ & & $\dot{\text { m }}$ & \\
\hline & 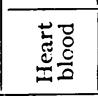 & & $\dot{\Omega}$ & $\dot{\Xi}$ & & 0 & $\dot{\Omega}$ & $\dot{\text { Q }}$ & 0 & & & 0 & \\
\hline & 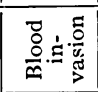 & & + & + & & & + & + & 0 & 0 & & 0 & \\
\hline & 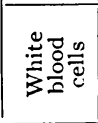 & 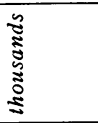 & \|\|$_{\infty}^{0}$ & $11 \stackrel{0}{\infty}$ & & $1 \stackrel{2}{2}$ & $\Lambda_{\infty}^{*}$ & $\wedge_{i}^{0}$ & 11 & & $v^{m}$ & $v_{\text {I }}^{0}$ & \\
\hline \multicolumn{2}{|c|}{ 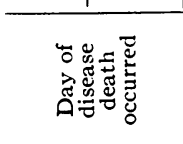 } & 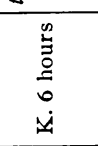 & 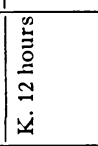 & 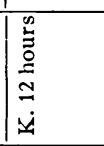 & 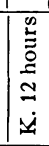 & 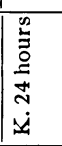 & 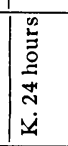 & 萧 & 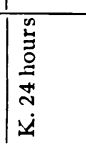 & 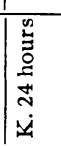 & 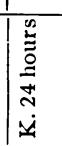 & 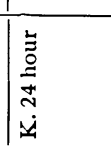 & \\
\hline \multicolumn{2}{|c|}{ 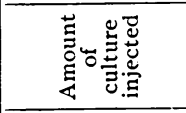 } & $\dot{u} \stackrel{n}{0}$ & $\stackrel{2}{0}$ & $\stackrel{2}{\dddot{n}}$ & 足 & $\ddot{d}$ & $\ddot{0}$ & $\stackrel{\leftrightarrow}{\circ}$ & $\stackrel{1}{2}$ & $\stackrel{n}{0}$ & $\stackrel{4}{0}$ & $\stackrel{0}{0}$ & \\
\hline \multicolumn{2}{|c|}{ : } & $=$ & - & - & $=$ & - & - & - & $H$ & - & - & - & \\
\hline \multicolumn{2}{|c|}{ 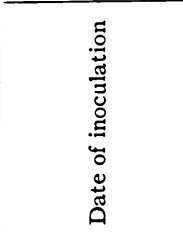 } & 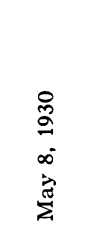 & 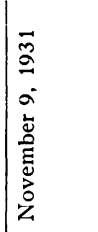 & 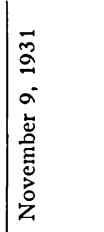 & 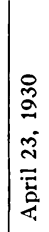 & 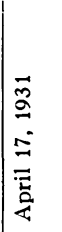 & 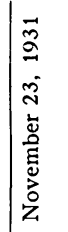 & $\begin{array}{l}\overrightarrow{\tilde{a}} \\
\tilde{a} \\
\tilde{a} \\
\overline{\bar{a}} \\
\bar{\alpha}\end{array}$ & 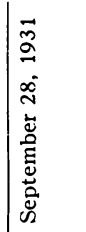 & 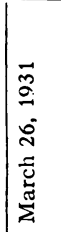 & 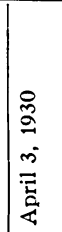 & 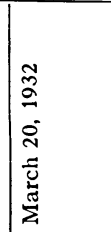 & \\
\hline \multicolumn{2}{|c|}{ 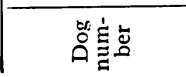 } & 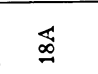 & $\stackrel{\infty}{\infty}$ & $\approx$ & | & $\stackrel{\vartheta}{z}$ & $\mid \begin{array}{l}\text { 艺 } \\
\text { | }\end{array}$ & $\frac{m}{m}$ & $\mid \frac{0}{N}$ & \ & 4 & 贫 & \\
\hline
\end{tabular}


almost entirely cellular, made up chiefly of red blood cells; but in certain places polymorphonuclear leukocytes were numerous, and in some alveoli equal to the red blood cells in number. Hemorrhages obliterating the structure of a number of alveoli were common. Surrounding this central area was a zone of alveoli filled in some places with edema fluid, in others with starch. Large pigment-bearing cells were present here and there in the alveoli-not more than one to several alveoli. Starch was seen in

Fig. 1. Dog 58. X-Ray of Excised Lungs Removed 1 Hour after Injection of $0.5 \mathrm{cc}$. Pneumococcus Type I Culture

Shows shadow of beginning lesion.

the lumen of several bronchi. The alveoli of the uninvolved tissue appeared to be normal.

The most striking change in the blood vessels of the lesion was the frequent extensive perivascular edema, and in Dog 58, perivascular hemorrhage, of the larger veins and arteries. Moderate engorgement of the capillaries and small blood vessels was present in the areas of exudation. In those areas where the alveoli contained only starch, no capillary dilatation was evident. The epithelium of the bronchi showed signs of injury. In the lumina of several bronchi there occurred varying amounts 
of cellular exudate consisting chiefly of red blood cells, but with some polymorphonuclear leukocytes intermixed. The peribronchial tissue of several bronchi was infiltrated with polymorphonuclear leukocytes.

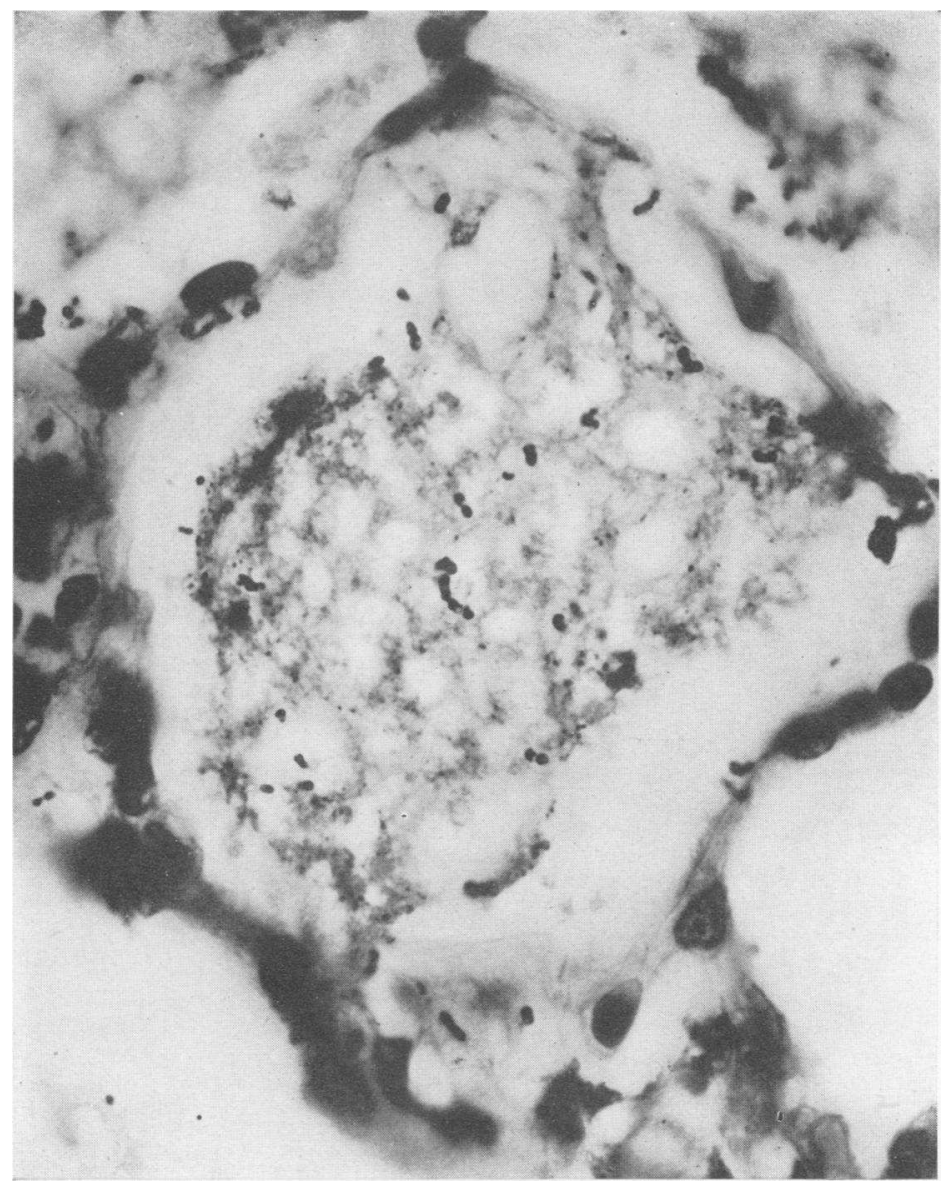

Fig. 2. Dog 32D. Killed 1 Hour after Injection of 0.25 cc. Pneumococcus Type I Culture

Numerous pneumococci are seen in the starch-filled alveolus. $\times 1200$.

Pneumococci were abundant all through the lesion-lying in the starch, edema and cellular exudate. Figure 2 shows pneumococci in a starch filled alveolus. In the normal lung, extending some distance from the involved area, pneumococci were observed to be in the alveolar walls. In places they were found singly or in chains of 2 to 3 pairs (Fig. 3). In other areas they were present in small clumps apparently growing within a small vessel at the junction of several alveoli-probably the atrial wall. Many of the alveoli were filled with edema fluid but contained no pneu- 
mococci. ${ }^{2}$ Phagocytosis by the polymorphonuclear leukocytes was not observed, and only a very occasional pneumococcus was detected within the macrophages.

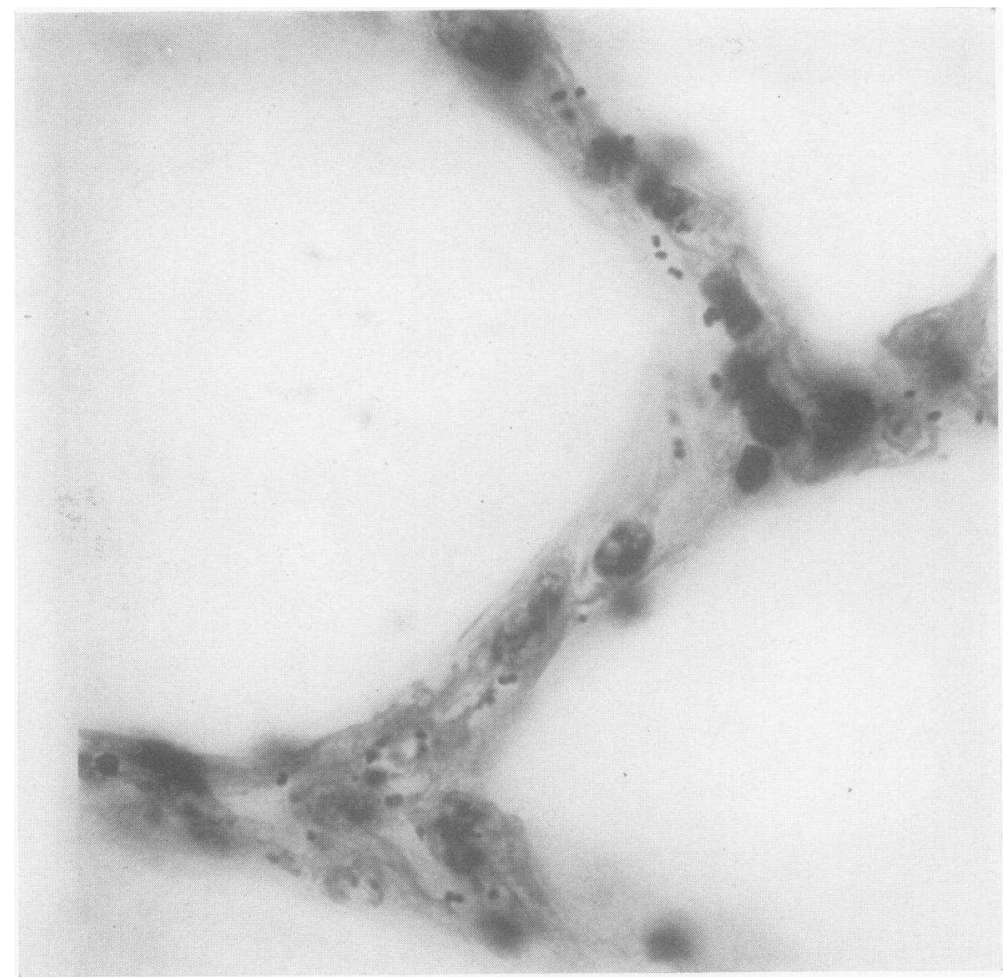

Fig. 3. Dog 32D. Within an Hour after their Implantation Pneumococci are Seen in the Walls of Apparently Normal Alveoli Some Distance aWAY From the Lesion. $\times 1200$.

Fibrin was seen in some parts of the cellular exudate. This consisted, for the most part, of fine strands irregularly placed, but in an occasional alveolus there was the typical basket-like arrangement seen in the human lesion, and also fibrin extending from one alveolus to another through the so-called alveolar pores. Small amounts were present in some parts of the pleura.

\section{Three hour lesion}

Dogs killed three hours after injection (Table I) showed much the same macroscopic appearance but the lesion was a little larger in extent, 3 to $3.5 \mathrm{~cm}$. in diameter, and firmer to the touch. Surrounding the lesion in one $\operatorname{dog}(4 \mathrm{~B})$ the surface of the lung was slightly depressed, perhaps

${ }^{2}$ One cannot, of course, conclude from this observation that pneumococci were absent from the alveolus. 
$0.5 \mathrm{~mm}$., in a zone $1 \mathrm{~cm}$. wide. In a second dog this appearance was lacking, but the anterior posterior diameter of the lesion was a little smaller than that of the adjacent lung tissue.

Microscopically, the areas of infiltration were somewhat more widespread than shown after 1 hour, but similar in distribution (Fig. 4).

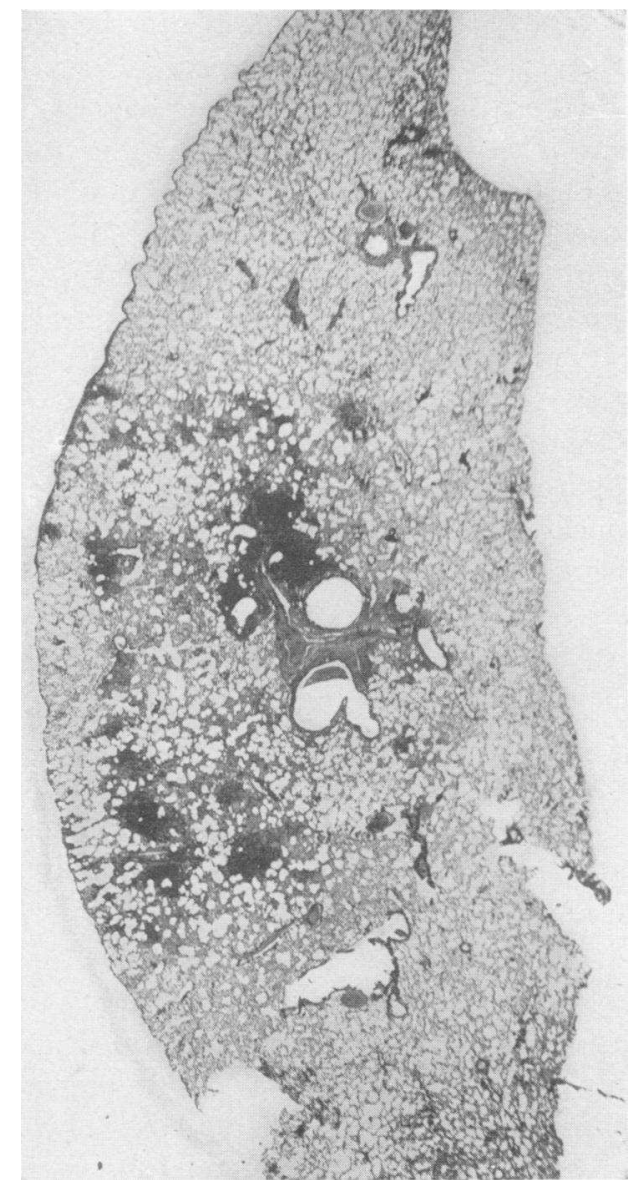

Fig. 4. Dog 59. Killed 3 Hours after Injection of 0.25 cc. Pneumococcus Type I Culture

Shows distribution of initial lesion, part of which is peribronchial. $\quad \times 4$.

Other changes were an increasing engorgement of the blood vessels, large and small. In Dog 59 there was marked dilatation of the pleural vessels where numerous subpleural hemorrhages were seen. This appearance was present not only over the infiltrated areas but extended for some distance over apparently normal lung tissue. Dog 47B did not show this picture. Blood vessels in the infiltrated areas contained a large per cent 
of polymorphonuclear leukocytes. Perivascular edema was present, and in places marked, but the massive perivascular hemorrhage seen after 1 hour was not present here in either of the dogs. Some of the larger bronchi showed pronounced peribronchial edema. The alveolar exudate in the central zone contained many more polymorphonuclear cells than at 1 hour and the bronchial exudate was made up almost entirely of polymorphonuclear cells. The alveolar walls in the infiltrated areas did not stand out sharply. However, they appeared to be intact. In many places they were thicker than normal, showing engorged capillaries, some edema and cellular infiltration. The surrounding lung tissue of Dog 59 which was normal showed the alveoli in general of about the usual size. In several small areas, however, they were partially collapsed. In the depressed zone, seen on the surface of the lung of $\mathrm{I}$ og 47 , the alveoli were of varying sizes, many open, many partly closed and some completely collapsed.

The distribution of the pneumococci was, in general, the same as after one hour with the difference that at three hours they were found in the walls of apparently normal alveoli far from the infiltrated areas. They began to appear in the alveolar spaces only after the exudation of edema. A further change was noted. In the areas infiltrated with polymorphonuclear cells, where the pneumococci were noticeably fewer in numbers than in the less infiltrated zones, beginning phagocytosis by the polymorphonuclear leukocytes and pigment-bearing macrophages was seen.

It is of interest to note that the white blood cells in the peripheral blood of Dog 47 showed no increase in number until the time of death, nor was there detectable invasion of the blood stream by pneumococci.

\section{Six hour lesion}

Until the six hour period the size of the infecting dose, which varied from $0.04 \mathrm{cc}$. to $0.5 \mathrm{cc}$., appeared to have little effect on the character of the lesion. At this time, however, a marked difference between the extent of the lesions initiated by large and small doses was observed. This consisted principally in much more pronounced zones of edema surrounding the primary lesions of the animals receiving the larger quantities of culture, and was best demonstrated by x-ray of the excised lung. Two dogs receiving infecting doses of 0.04 and $0.05 \mathrm{cc}$. showed a shadow only 0.5 to $1 \mathrm{~cm}$. greater in diameter than the consolidated macroscopic lesion (Fig. 5). On the other hand, the dogs given $0.25 \mathrm{cc}$. to $0.5 \mathrm{cc}$. pneumococcus culture showed edema of the major portion or the entire lobe surrounding a relatively small area of consolidation (Fig. 6). The gross external appearance of the central lesion was much the same as that obtained at three hours but somewhat darker red and more sharply outlined. It was nodular to the touch but fairly firm. The remainder of the lobe in Dogs 
18A, 11D and 48B felt normal, while the whole lobe of Dog $1 \mathrm{~A}$ and twothirds of the lobe of $46 \mathrm{D}$ was boggy. In two of the dogs, $18 \mathrm{~A}$ and $48 \mathrm{~B}$, there was a zone of slightly depressed surface, about $1 \mathrm{~cm}$. wide, surrounding the lesion. In the other two this was absent. On cut section a clear or slightly sanguineous fluid oozed from the surface which was of a redpink, rather finely mottled appearance.

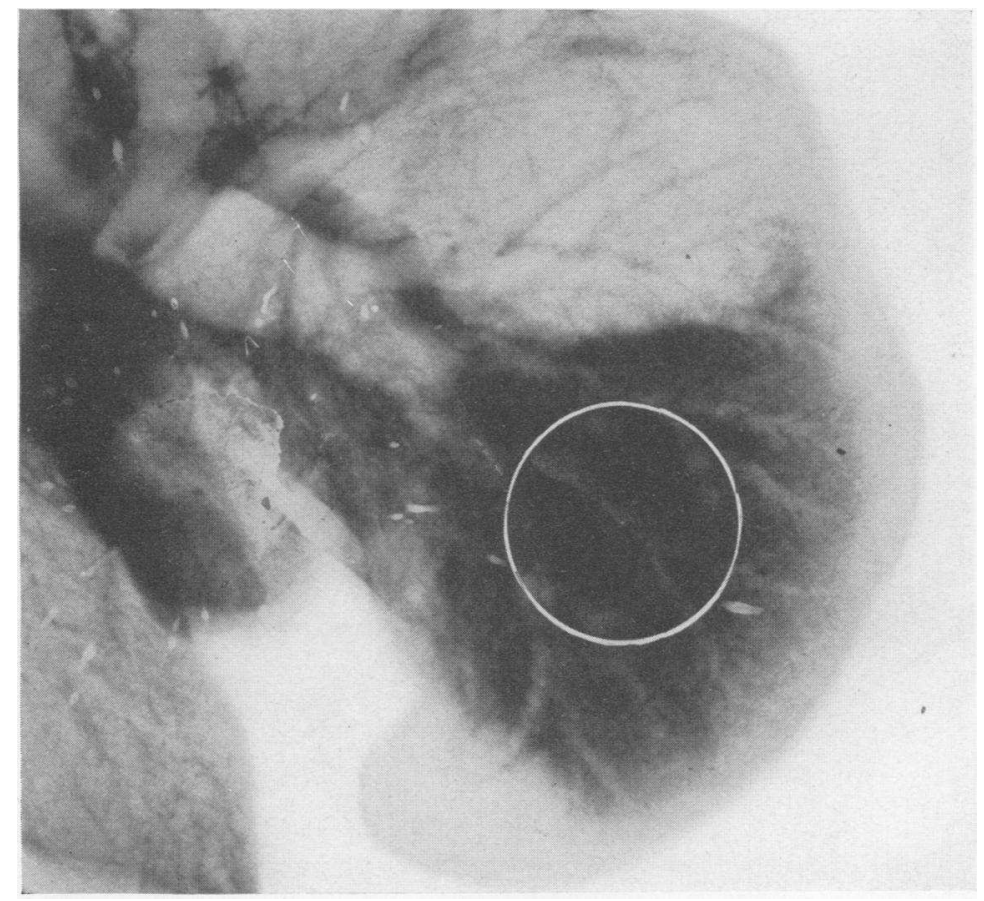

Fig. 5. Dog 48B. X-RAy of Excised Lungs

Dog killed 6 hours after injection of $0.04 \mathrm{cc}$. pneumococcus Type I culture. White circle indicates area of macroscopic consolidation. Shadow surrounding circle is due to edema.

The microscopical picture, under low magnification, showed a much more continuous cellular infiltration than did the sections at three hours (Fig. 7). The oldest parts of the lesion now began to give the characteristic appearance of lobar pneumonia in man, namely, sharply outlined alveolar walls, surrounding an exudate composed chiefly of polymorphonuclear leukocytes. This was most marked in the dog receiving the largest dose (Fig. 8). Of much interest is a comparison of sections of a very early lobar pneumonia, six to twelve hours old ${ }^{3}$ from a human being,

3 This patient, postoperative from a brain tumor removal, had a sharp rise in temperature six hours before death. At postmortem a uniform consolidation of the right upper lobe was found, from which a Group IV pneumococcus was isolated. 
with the experimental lesion at six hours. The microphotograph of the human lesion shown in Figure 9 resembles quite closely that of Dog 1A (Fig. 8). The architecture of the lung in the experimental lesion was, on the whole, well preserved. Here and there the walls of alveoli were

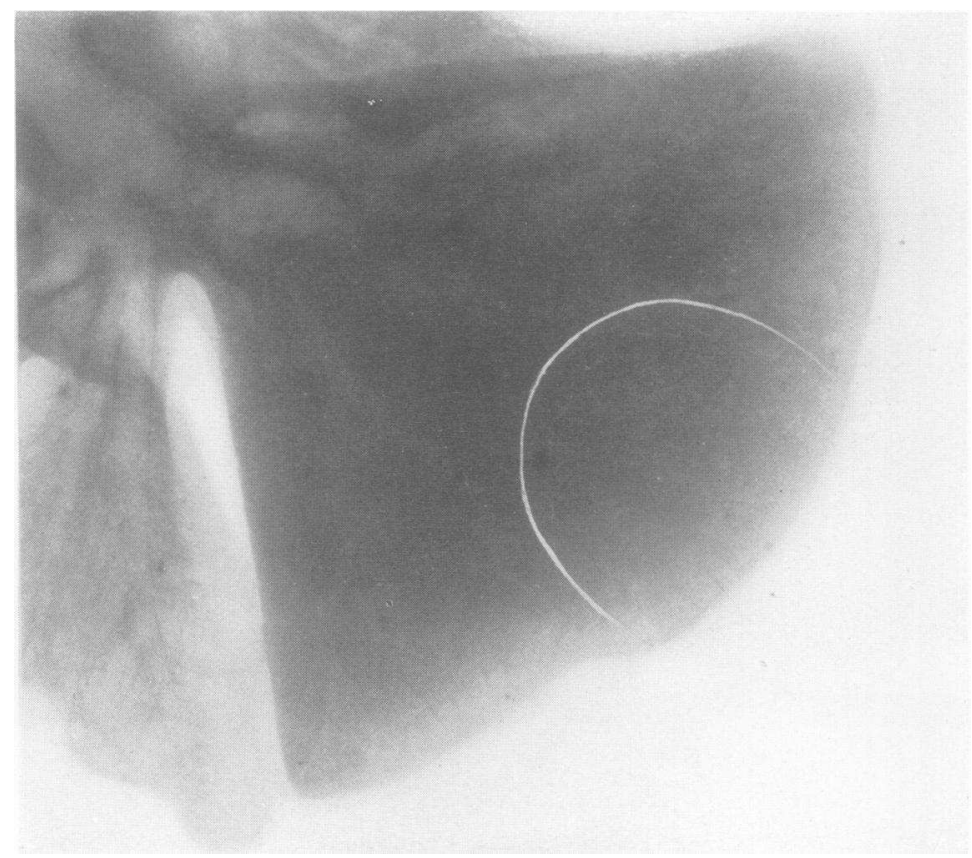

Fici. 6. Dog 1.A. X-Ray of Exciseid I.ungs

Dog killed 6 hours after injection of 0.5 cc. pneumococcus Type I culture. White semicircle indicates area of macroscopic consolidation. Shadow comprising the remainder of the lobe is due to edema. IDifference between Dogs $1 \mathrm{~A}$ and $43 \mathrm{~B}$ in extent of edema appears to be related to size of infecting dose.

ruptured by edema. Scattered through the section were numerous lacunae. In Dogs $18 \mathrm{~A}$ and $48 \mathrm{~B}$ there was partial collapse of the alveoli in places beyond the zone of edema which was now much wider than was observed at three hours. The capillaries were everywhere more dilated and contained a much larger percentage of polymorphonuclear leukocytes than was observed previously (Fig. 10). The increased thickness of the alveolar walls appeared to be due to distention of the blood vessels rather than to edema or cellular infiltration into their substance, although interstitial infiltration was noticed in places. The exudate consisted of red blood cells and polymorphonuclear cells. Mononuclear cells, other than lymphocytes, formed a very small percentage of the cells. The large pigment-bearing macrophages did not appear in greater numbers than in the earlier stages. The perivascular edema of the large vessels had in- 
creased in extent, and more fibrin was present, confined largely to the alveolar spaces and areas of perivascular edema. The bronchial and peribronchial tissues showed no further change that was significant.

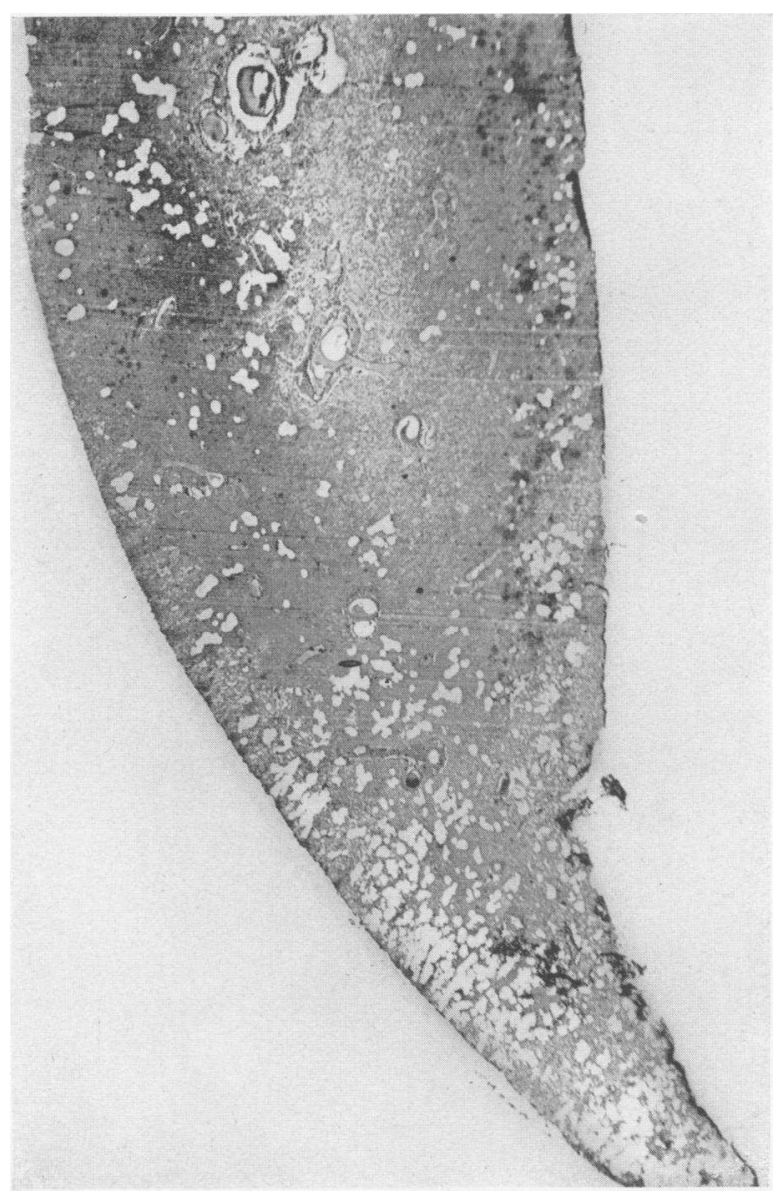

Fig. 7. Dog 1A. Section through Lesion in Right Lower Lobe Shows Increasing Extent and Evenness of Infiltration as Compared With 3 Hour Lesion in Figure $4 . \times 4$.

Pneumococci were present in very small numbers, even in the dog receiving $0.5 \mathrm{cc}$. of culture. It was of ten only after considerable search that an occasional one was seen within a cell or in the zone of edema.

\section{Twelve hour lesion}

At twelve hours the lesions were larger, darker in color, firmer to the touch and more continuous than those observed at six hours. In the two instances of pneumococcus Type I infection (Dog 13D and 18D, 
Table I) the greater part of the initially infected lobe was consolidated, and the disease had spread to adjacent lobes and the hilum of the opposite side. X-rays of the excised lungs of these animals, not only showed opacities larger in extent than the macroscopic areas of consolidation, but also

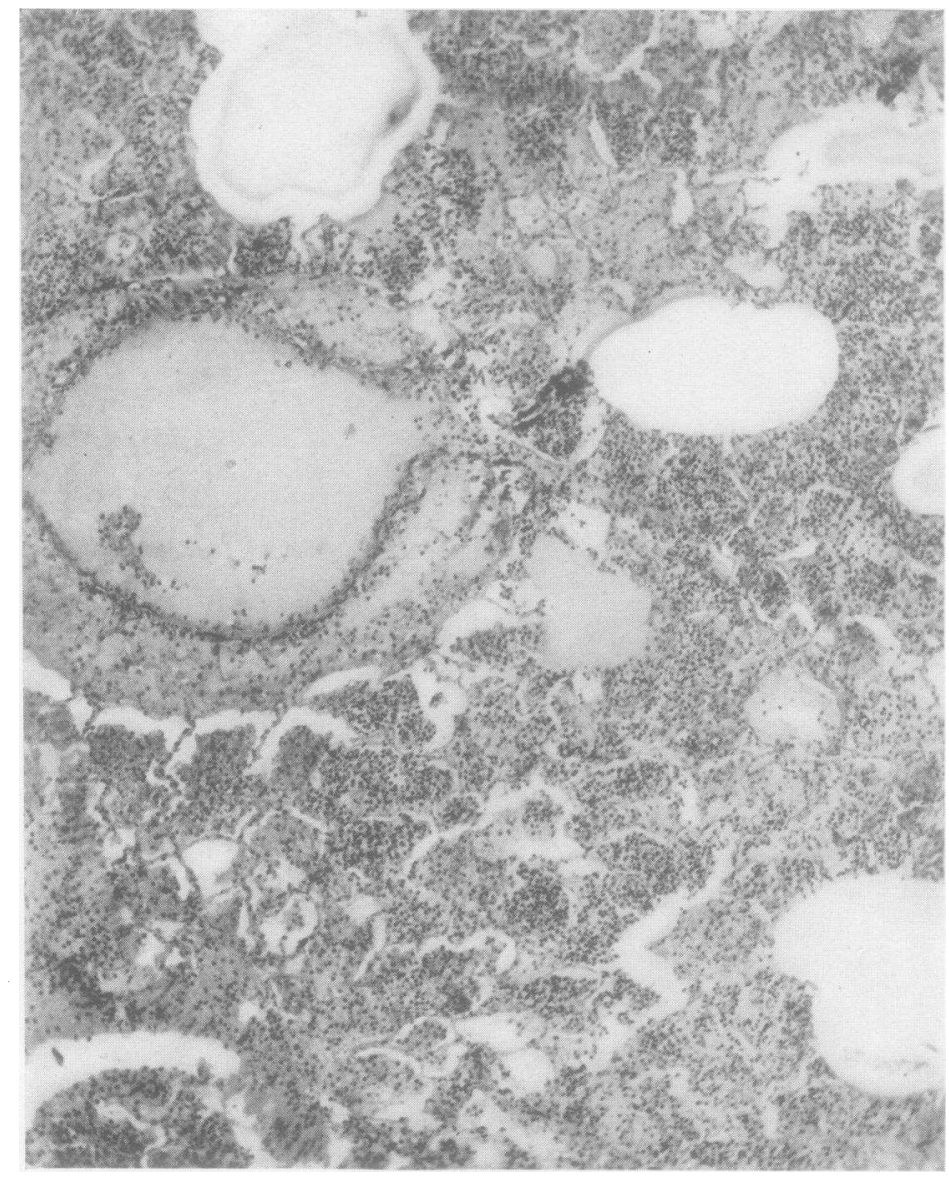

Fig. 8. Dog 1A. Higher Power View of Figure 7 Showing STRUCTURE OF LESION

Note general resemblance to histology of early human lesion shown in Figure 9. $\times 85$.

revealed infiltration in lobes which appeared normal to the eye, indicating the widespread distribution of edema at this stage. The third dog, 13A, infected with pneumococcus Type II, showed a much smaller lesion, confined entirely to one lobe. By this time fine strands of fibrin began to appear on the pleura over the consolidated areas. On the cut surface the oldest part of the lesion appeared brownish red, slightly granular and only 
moderately moist. The most recently involved areas were very moist. The lymph gland at the hilum of the affected lobe was swollen and edematous. Microscopically, the lesion was seen to be more nearly continuous than at six hours. Many fields under low magnification showed no lacunae. The perivascular edema was still pronounced, and the peri-

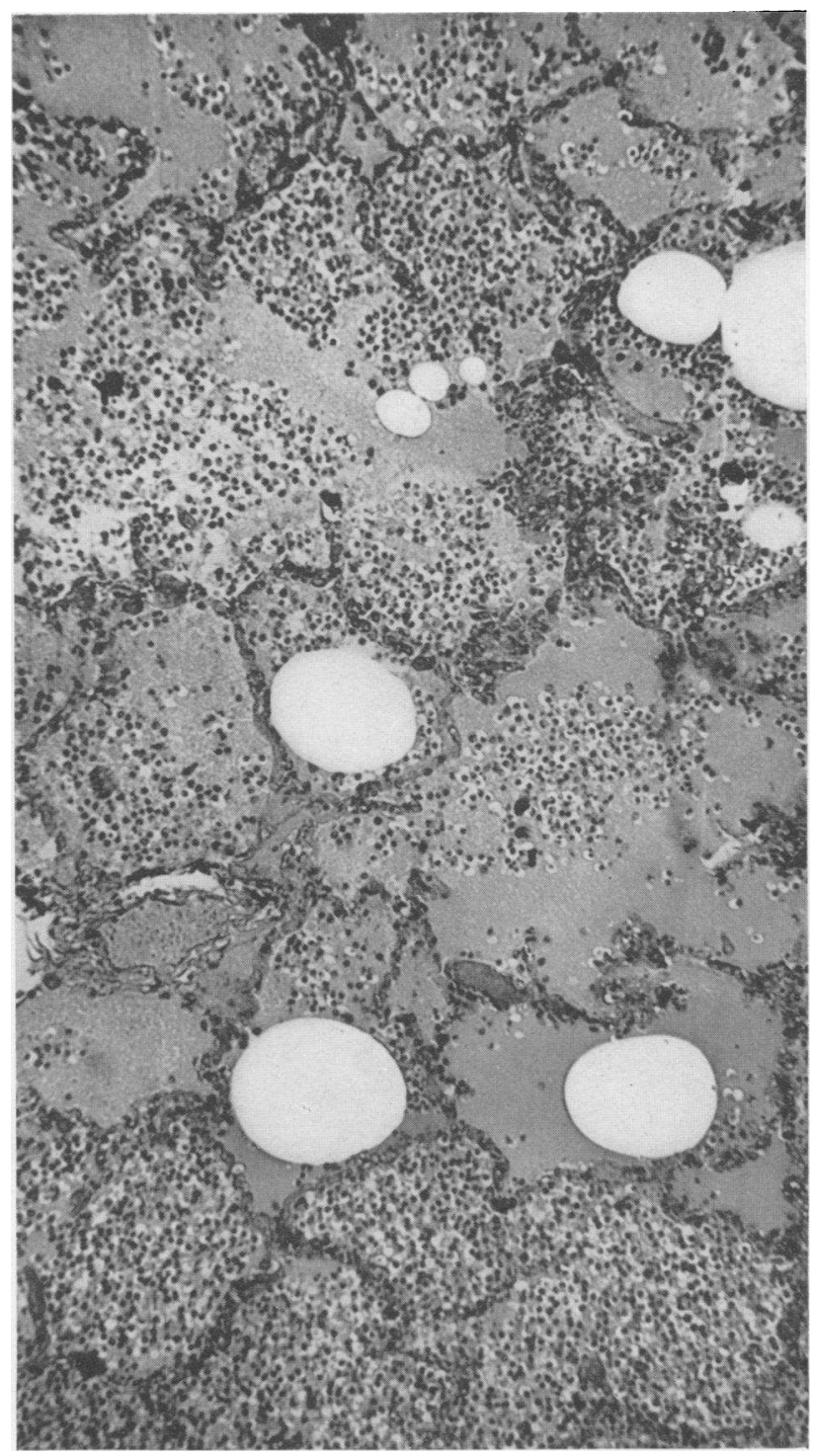

Fig. 9. Human lobar Pneumonia

Patient died within 6 to 12 hours of onset. Distribution of exudate is irregular. Lacunae numerous. $\times 110$. 
bronchial edema greater than before, and in places hemorrhagic. Fibrin was more abundant in the alveoli. Infiltration of the pleura with polymorphonuclear leukocytes, red blood cells and fibrin was seen.

The distribution of pneumococci in the different parts of the lesion was seen very clearly at this stage. Pneumococci were much more abundant,

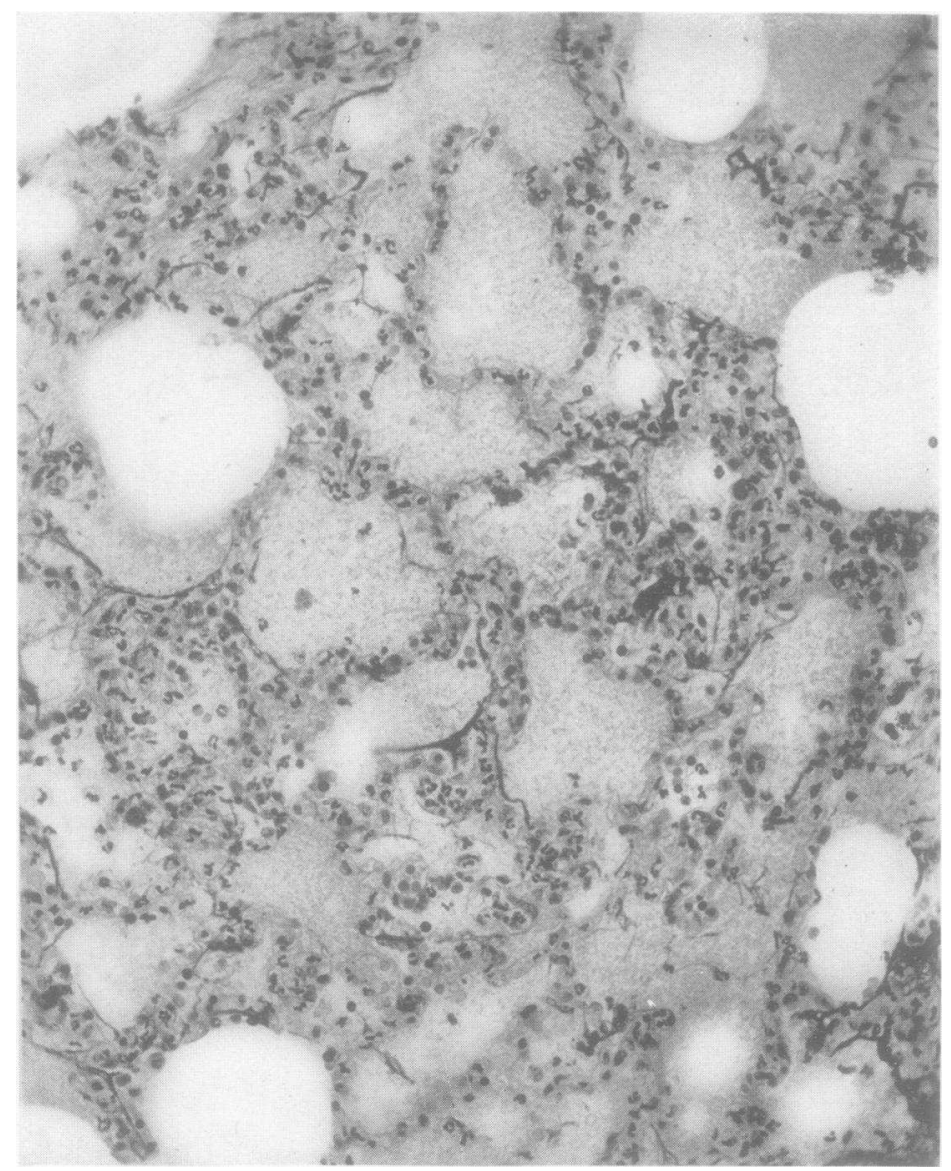

Fig. 10. Dog 48B. Killed 6 Hours after Injection of $0.04 \mathrm{CC}$. Pneumococcus Type I Culture

Section through advancing margin of lesion shows thickening of intraalveolar septa due chiefly to distention of capillaries carrying large numbers of polymorphonuclear leukocytes. $\times 230$.

in certain zones of the lesion, than at the six hour period. Beyond the zone of edema pneumococci were seen in the walls of apparently normal alveoli, but not in as large numbers as was observed at three hours. Around the periphery of the consolidated area, lying within the edema filled alveoli, pneumococci were present in great numbers (Fig. 11). 
Here and there pneumococci were seen in the alveolar wall. Some of the alveoli appeared to contain very few or none. Proceeding from this zone toward the main lesion, polymorphonuclear leukocytes and red blood cells began to appear in the lumina. The pneumococci were still abundant and lay, for the most part, free in the edema fluid, but here and there one or

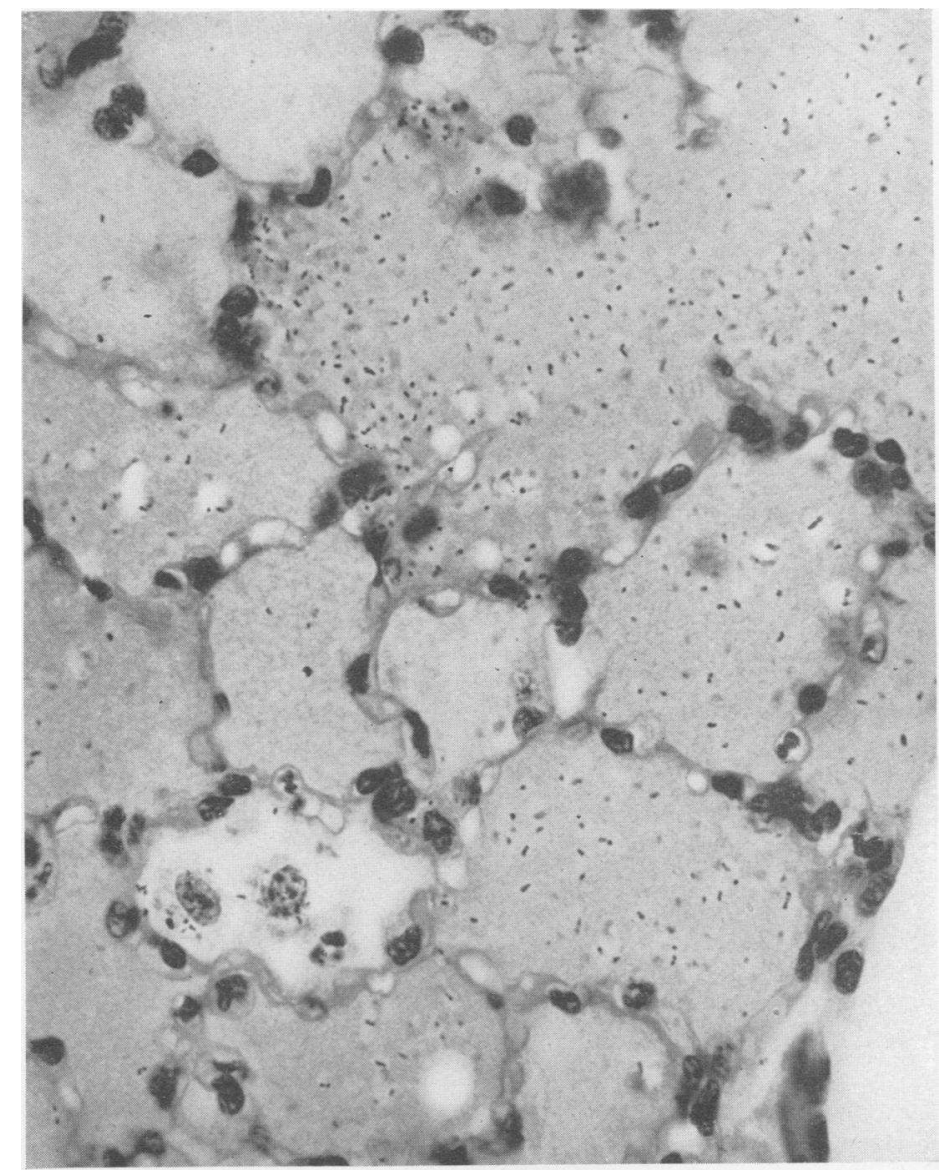

Fig. 11. Dog 13D. Killed 12 Hours after Injection of 0.25 cc. Pneumococcus Type I Culture

Section through advancing margin of lesion showing large numbers of pneumococci in edema-filled alveoli. Some appear to lie in the alveolar walls. $\times 700$.

two were seen within the leukocytes (Fig. 12). Nearer the area of intense cellular infiltration the pneumococci were fewer in number, more and more were within the leukocytes, and in the oldest part of the lesion the microorganisms were relatively rare and practically entirely intracellular (Fig. 13). The frequent presence of poorly stained pneumococci inside the 
leukocytes in this area would indicate the occurrence of intracellular digestion. No particular differences were noted at this time between dogs receiving larger and smaller infecting doses.

In two of the animals in which detailed observations were made on the blood, the number of white blood cells had changed very little by the end

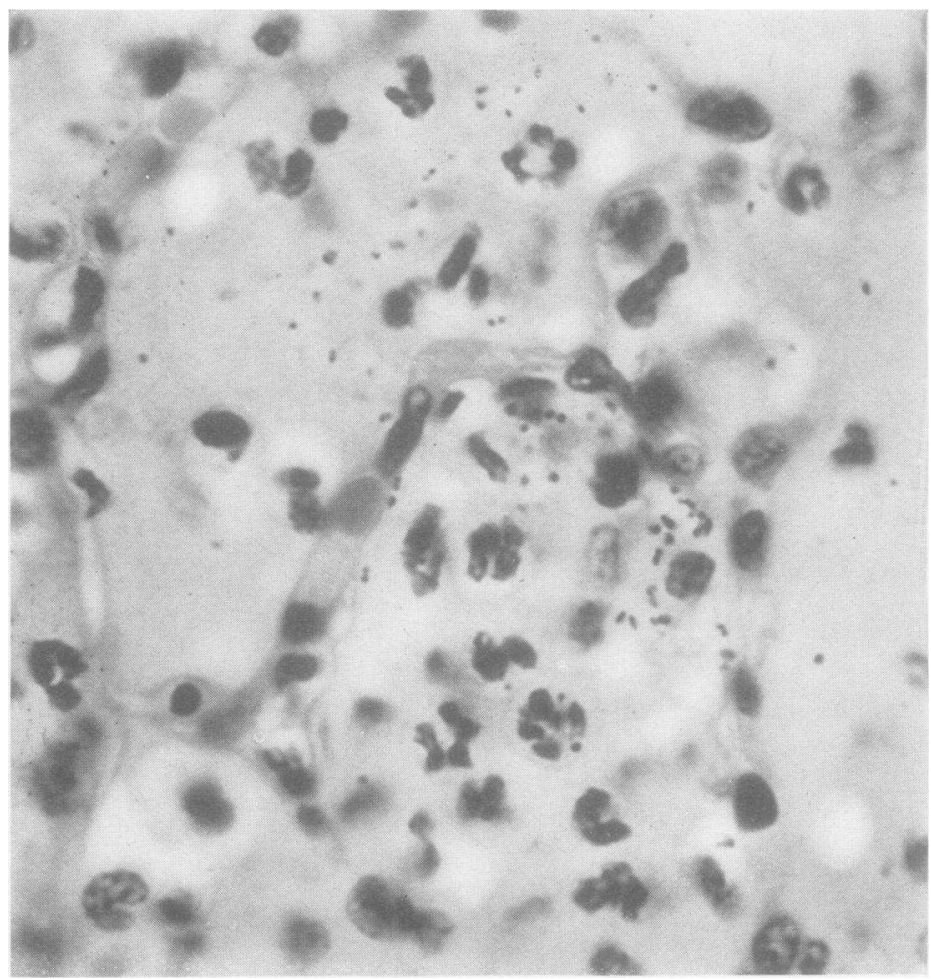

Fig. 12. Dog 13D. Section through Area of Beginning Cellular INFILTRATION UNDERLying EDEMa ZONE

Pneumococci are numerous and for most part lying free in edema, but a few have been engulfed by the polymorphonuclear leukocytes. $\times 1240$.

of twelve hours. Pneumococci were present in the blood of both dogs, 13D and 18D (Table I).

\section{Twenty-four hour lesion}

After twenty-four hours the lesion had usually occupied one entire lobe, and sometimes had spread to other lobes. The more extensive involvement was likely to be found in animals receiving larger infecting doses. In four of the seven dogs killed after twenty-four hours (Table I), the affected lobe was evenly consolidated, firm, of liverlike consistency and airless. The cut surface showed a quite uniform brownish color, was 
moderately moist and somewhat granular. From the larger bronchi there oozed a serous fluid. Three of the dogs showed a consolidation of one or more lobes which was distinctly less smooth and firm in character than the others. One of these dogs (2A) was infected with a fatal dose. Another (31B) suffered from an unusually marked morphine depression, and the third (19C) was an old animal. Fine threads of fibrin were seen

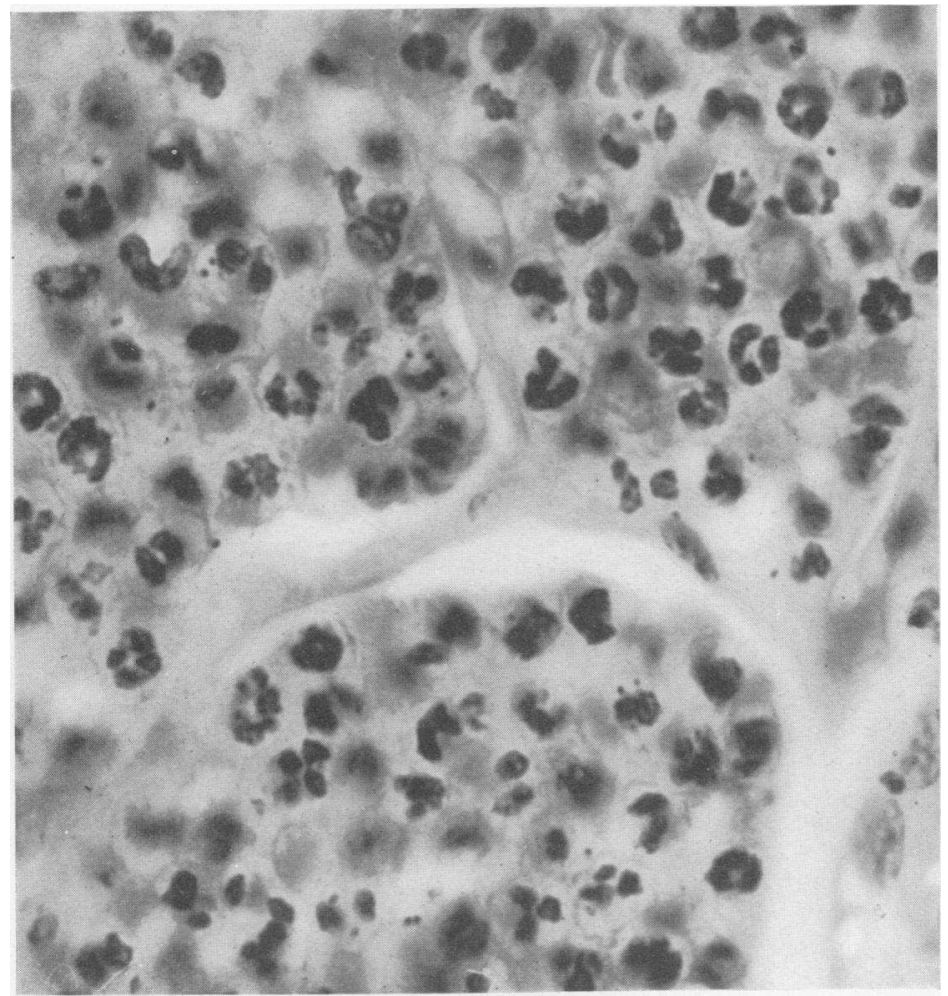

Fig. 13. Dog 13D. Section through Central Part of Lesion Showing Intense Intra-Alveolar Exudate Consisting Chiefly of PolyMORPHONUCLEAR LEUKOCYTES.

Pneumococci few in number and almost entirely intra-cellular. $\quad \times 1240$.

spreading over the surface of the consolidated lung in all instances. The pleural cavities were dry. Frequently the margin of the advancing consolidation was very sharp. Figure 14 shows the lesion at twenty-four hours in a lung which has been perfused with salt solution to bring out the contrast between the involved and uninvolved portion of the lobe. A small patch of early consolidation is seen in the mid portion of the left upper lobe. When infection was initiated in the right lower lobe there was almost always a small area of air-containing tissue 1 to $2 \mathrm{~cm}$. in diameter at the upper posterior tip of the lobe. 
Definite histological differences between the evenly consolidated and the unevenly or irregularly infiltrated lungs were observed. A section taken through the length of a firmly consolidated lung showed a practically continuous inflammatory exudate (Fig. 15). The lacunae, seen in the earlier sections, were no longer present, except toward the spreading

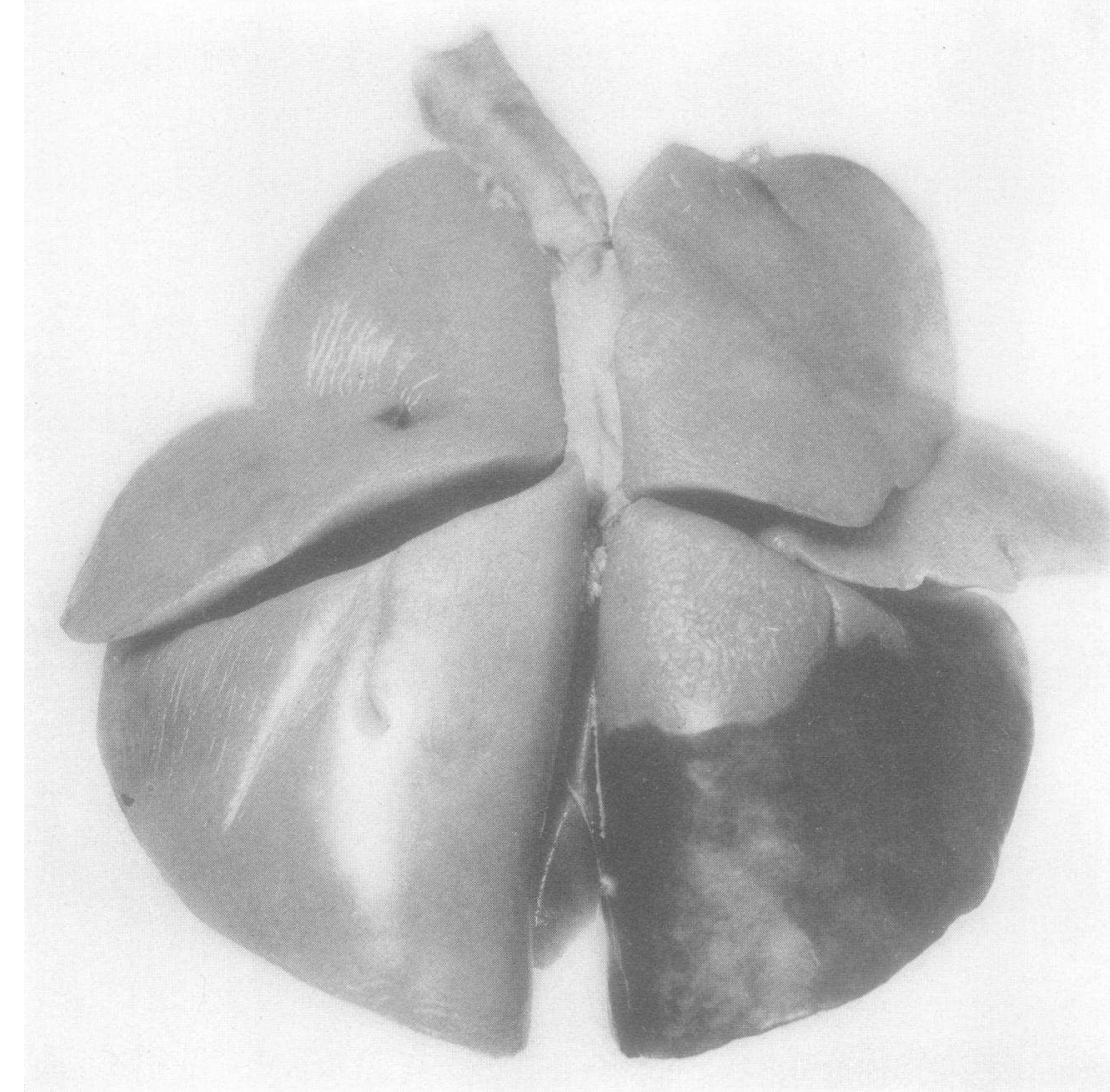

Fig. 14. Dog 6A. Killed 24 Hours after Injection of 0.5 cC. Pneumococcus Type I Cultere

Lungs perfused lobe by lobe with salt solution. Note sharp margin of consolidated portion of right lower lobe and beginning lesion in center of left upper lobe.

edge. The alveoli were evenly filled and frequently distended with cells. Here and there, perhaps on every two or three low power fields, were seen small groups of alveoli containing edema with few or no cells (Fig. 16). The alveolar walls were well marked but the capillaries less dilated than at twelve hours. In several small areas, chiefly at the periphery of the oldest part of the lesion (Dog 41B) just under the pleura, the characteris- 
tic macrophagic reaction, observed in beginning resolution, was present. The microscopical picture of the lungs of the three animals, showing more extensive and less even consolidation, lacked the uniform appearance of the firmly consolidated process. Groups of alveoli containing cellular

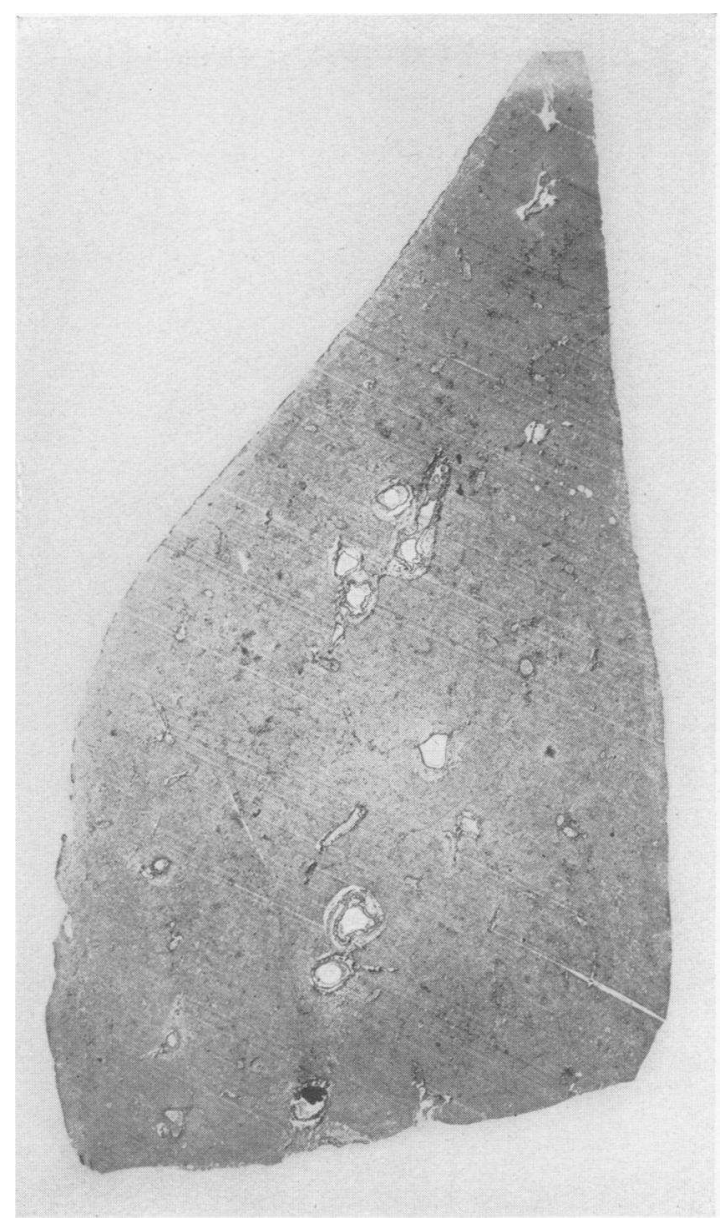

Fig. 15. Dog 41B. Killed 24 Hours after Injection of 0.04 cC. Pneumococcus Type I Culture

Section through large portion of right lower lobe. Note continuous and even character of infiltration. $\times 4$.

exudate alternated with edema-filled alveoli. Numerous lacunae were seen. Red blood cells formed a large part of the cellular exudate. The architecture was well preserved except in some areas of edema. No evidence of a macrophagic reaction was observed. This lesion had the character of a coalescing lobular pneumonia. 
The distribution of pneumococci was likewise very different in these two types of lesions. In the lungs showing the intense consolidation of lobar pneumonia, marked variations in the numbers of pneumococci present in the different parts of the lesion were noted, as described in the twelve hour lesion. In the oldest parts of the lesion, and especially in the

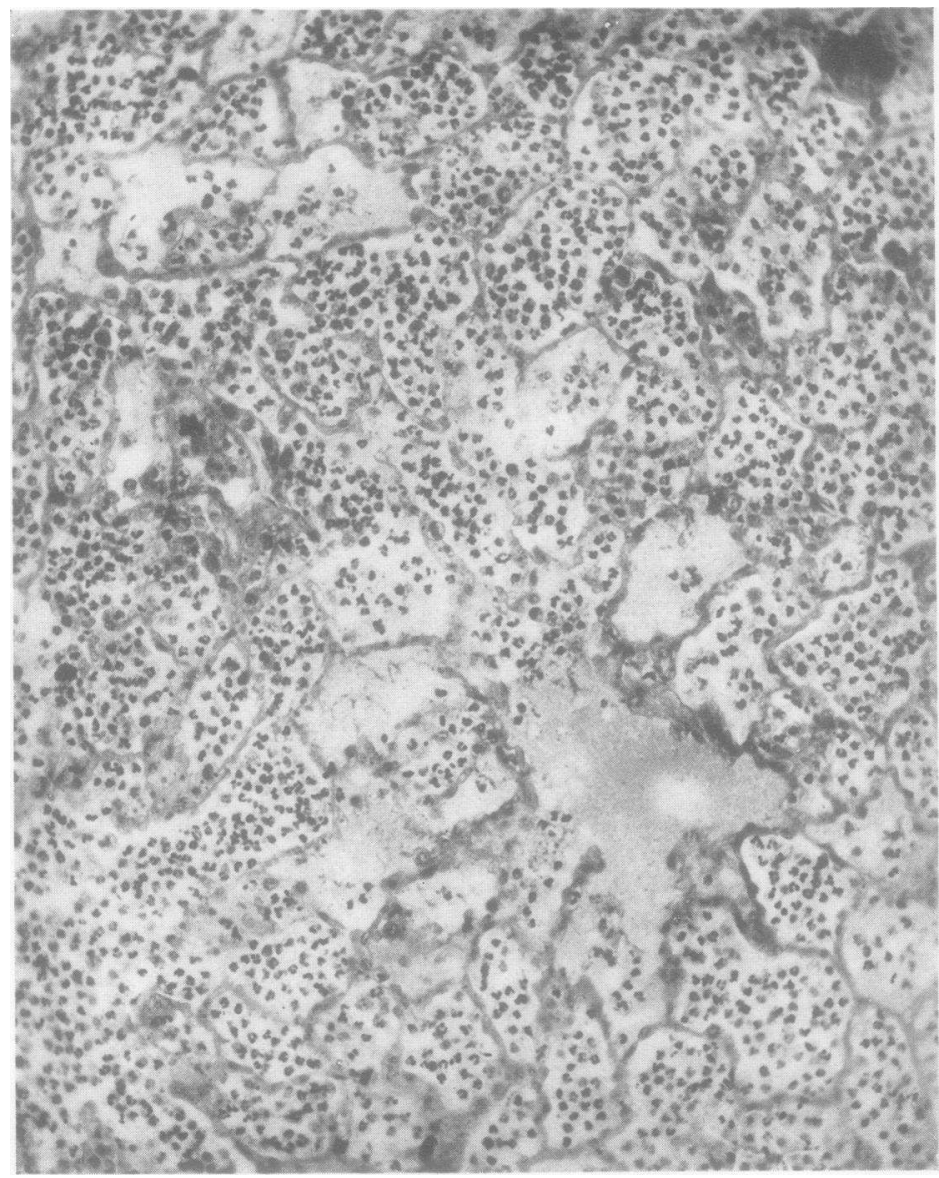

Fig. 16. Dog 41B. Higher Power View of Figiere 15 Showing Structure

Sharply defined alveolar markings give mosaic-like appearance characteristic of human lesion. $\times 230$.

areas of beginning macrophagic reaction, microorganisms were even fewer than they were at twelve hours. On the other hand in the coalescing lobular pneumonic lesions, pneumococci were seen in great numbers all through the inflammatory process, fewest in the areas of polynuclear leukocytic exudate, but occurring both extracellularly and intracellularly. In some areas they were present in masses. 


\section{Rôle played by starch}

With a view to determining what part starch might play in creating conditions favorable for the inception of the disease, a number of dogs were injected with $1 \mathrm{cc}$. of sterile starch. Some of these animals were killed at intervals of from one hour to forty-eight hours; others were kept under observation to determine fluctuations in temperature and white blood cell counts and for evidence of lung opacities by x-ray. Smears and cultures of the lesion were made to exclude bacterial contamination.

In the one hour lesion very little reaction was observed. The only definite evidence of irritation was slight occasional perivascular and peribronchial edema. The alveoli filled with starch were free from cells. By the end of six hours a well marked inflammatory lesion had occurred, similar in many respects to the six hour lesion produced by the smaller doses of pneumococci. It differed from the pneumococcus lesion, however, in several respects. First, the intra-alveolar cellular exudate was much more hemorrhagic in character, the lung architecture was not as well marked, and the zone of edema surrounding the well infiltrated area was narrower. The other changes, such as perivascular and peribronchial edema, polymorphonuclear leukocytic exudation, deposition of fibrin, etc., were all found, though they were less marked.

The lesion caused by starch did not show progressive growth in size, since animals sacrificed at 20 and 48 hours respectively revealed small liver-colored nodules 1 to $2 \mathrm{~cm}$. in diameter at the site of injection, surrounded by normal lung tissue. At the end of 20 hours a well marked macrophagic reaction was evident and the alveoli were clearing.

The foregoing findings indicate that starch of itself will produce a localized inflammation of the lung, which, however, does not spread and which does not produce a detectable constitutional reaction.

\section{Part played by atelectasis}

On account of the prominent rôle recently assigned by Coryllos and Birnbaum (3), Henderson et al. (4) and others, to pulmonary atelectasis as an etiological factor in the inception of lobar pneumonia, particular attention has been paid to this matter in the foregoing study. Data for the determination of the presence of atelectasis were obtained from several sources; first, the position of the heart and diaphragmatic shadows in the $\mathrm{x}$-ray; second, direct observation of the lungs of animals killed or dying at different times during the disease; third, microscopical examination of the lung tissue.

A study of the X-rays, as described in Paper I of this series (2) showed a displacement of the heart shadow toward the affected side, or elevation of the diaphragm, in less than half the experimentally infected dogs. The degree of displacement of the heart shadow appeared to depend largely on 
the nature and rate of the pulmonary involvement. With a well localized and slowly spreading lesion there was either no detectable shift or only a slight one. When the pulmonary process spread rapidly, a marked displacement of the heart shadow to the affected side occurred. Resolution was also accompanied by a movement of the heart to that side. The reason for the displacement of the heart in these instances was apparent at autopsy, since the irregularly consolidated or resolving lung was smaller than normal. The uniformly consolidated lung, however, was of approximately the same size, or only a trifle smaller, than the normally inflated one. The slight displacement of the heart and diaphragm, seen under these conditions, can be accounted for by fixation in the size of the lung due to lack of aeration, and the increased elastic tension which Van Allen and $\mathrm{Wu}$ (5) demonstrated as occurring in the experimental pneumonic lung.

In dogs killed three to six hours after the infecting dose, definite evidence of partial alveolar collapse, in the form of a narrow zone of depressed surface surrounding the initially infiltrated area, was occasionally found. Microscopic examination of this part of the lung showed partially or completely collapsed alveoli. Dissection of the bronchi, leading to these areas, failed to reveal obstruction of their lumina. In the twelve hour lesion this appearance was not observed. At this time the alveoli at and beyond the margin of the spreading process were open, containing air or edema fluid. Later lesions either primary or secondary showed the same picture. Mucous plugs were found only fairly late in the disease in the bronchi of lobes showing gray hepatization or resolution.

\section{DISCUSSION}

The foregoing description of the series of changes observed during the development of the characteristic lesion of experimental lobar pneumonia in the dog provides a basis for certain assumptions concerning the mechanism of the initiation and propagation of this pathological process. Judging by the experiences of others, and our own, it would seem that implantation of the pneumococci within the alveoli is, if not essential, at least very important for the inception of pneumococcus infection in the lung of the dog. It is well known that foreign material is rapidly expelled from the normal lung as long as it is external to the ductus alveolaris. Once it passes through the bottle-neck of the ductus into the sacculus, elimination is much slower. The usefulness of starch versus a less viscus fluid is apparent in this regard. The starch-broth medium serves another purpose, namely that of providing a highly favorable environment for the multiplication of the implanted pneumococci. Immediately following the introduction of the pneumococcus-starch suspension into a terminal bronchus, and the surrounding primary anatomical units, ${ }^{4}$ a

${ }^{4}$ The anatomical classification of $\mathrm{Wm}$. Snow Miller (6) is used in this study. 
series of reactions indicative of local injury occur. These consist of local engorgement of the blood vessels, capillary hemorrhage into the alveoli, with destruction of the architecture in places, exudation of fluid both into the alveolar spaces and the perivascular and peribronchial tissues and the mobilization of polymorphonuclear leukocytes. What part the presence of growing pneumococci play in the production of these early pathological changes is not clear since starch alone will cause the same type of reaction, though less extensive, and it may well be that the preliminary local injury to the pulmonary tissue is an important factor in the initiation of the pneumococcus lesion.

The lesion spreads in a fairly regular manner. Around its periphery is a zone of alveoli filled with fluid. After a certain period polymorphonuclear leukocytes and red blood cells begin to appear in the exuded fluid and the cellular exudation proceeds until the alveoli are filled with cells and evenly distended. The edema does not become marked until the six hour period, at which time the spread of the lesion becomes accelerated. This picture of the mode of extension of the process in the dog appears to be identical with that described by Loeschcke (7) as occurring in lobar pneumonia in man. ${ }^{5}$ The early experimental lesion is of lobular distribution and may be termed a bronchopneumonia, since it is initiated in the lung tissue surrounding the terminal bronchi into which the pneumococci are injected. However, as the lesion grows this relationship to the bronchi no longer maintains. Lobules or contiguous groups of lobules become involved, and in the lesions produced by the usual non-lethal dose, the lobular picture disappears rapidly as the exudate becomes widespread and assumes a cellular character. On the other hand, following large fatal doses, and also in animals where depression from the preliminary morphine injection is prolonged, the lobular type of lesion may persist. The histological picture of early lobar pneumonia in man cited above, gives one much the same impression of a lobular distribution of the cellular exudate, but when compared with the early lesions in dogs, shows a greater area of the lobe in more or less the same stage of consolidation. Study of secondary foci in other lobes of the dog's lung shows that they progress through the same sequences of changes as described above.

Within a relatively brief period (one hour) after the implantation of the pneumococci, the organisms are observed to be migrating in all directions away from their primary locus. The route appears to be prin-

${ }^{5}$ The primary edema reaction to pneumococcus infection has been observed also by Permar (8) in experimental pneumonias of the lungs of rabbits and more recently by Rhoads and Goodner (9) in dermal pneumococcus infection of the rabbit. These last authors found that a marked edema of the tissues preceded cellular exudation and concluded that the spread of the edema fluid was the principal agent in the dispersion of the pneumococci through the tissues. 
cipally by way of the lymphatics and capillaries. ${ }^{6}$ At first the presence of pneumococci in the parenchyma does not seem to cause much disturbance. After a few hours, however, the alveolar septa become thickened, due, for the most part, to engorgement of the capillaries, but also, to a certain extent, to edema and cellular exudation. Blake and Cecil (10) observed this early migration of pneumococci through the interstitial tissues of monkeys with experimental lobar pneumonia, but in contrast to the picture in the dog, they found marked and widespread inflammation of the parenchyma of the lung in the invaded zone.

The manner in which the pneumococci are transported, after the first few hours, is not clear. At twelve hours great numbers of microorganisms are visible in the alveoli filled with fluid, but relatively few appear to be in the alveolar walls. It seems not impossible that they may be carried into adjacent lobules also in the edema fluid, by way of the smaller air passages. The fact that pneumococci were so infrequently seen in the six hour lesion, at which time the zone of edema became much greater, suggests that they are dispersed in this way. ${ }^{7}$ However, there still remains the question as to the cause of exudation of fluid into the alveolar spaces. Does it depend on the presence of pneumococci in the alveolar walls causing irritation and dilation of the lymphatics and capillaries, or is this effect produced by toxic products of the pneumococcus? The observation that sterile starch will cause this same picture in the neighborhood of the injected mass indicates the possibility of endothelial injury occurring at some distance from the growing pneumococci. According to Loeschcke (7) much of the spread of edema in the early lesion of lobar pneumonia in man is by way of the small air passages, and also through the interalveolar pores of Kohn.

The picture of the distribution of pneumococci in the twelve hour lesion as shown in Figures 11, 12 and 13 suggests an explanation of the very puzzling question as to how pneumococci can propagate in the lung of an animal whose blood possesses marked pneumococcidal properties. Previous studies have demonstrated that the power of the blood to kill pneumococci depends on opsonization, phagocytosis and intracellular digestion (11). ${ }^{8}$ Furthermore, the opsonic effect is dependent on a quantitative relationship between the concentration of opsonins in the

${ }^{6}$ The inference that pneumococci are spread by way of the capillaries may be questioned as lacking adequate evidence. It is only because pneumococci are seen in the alveolar walls, which according to $\mathrm{Wm}$. S. Miller (6) do not contain lymphatics, that this assumption is made. The authors know of no way of distinguishing lymphatics from partially collapsed capillaries.

${ }^{7}$ Loeschcke (7) believes that this is the chief method by which pneumococci are spread in the human lesion.

${ }^{8}$ The blood serum of the dog as well as that of other animals has no growthinhibiting effect but on the contrary provides an excellent medium for the multiplication of pneumococci. 
serum and the number of pneumococci present. Increasing the number of pneumococci beyond a certain optimum ratio of microorganisms to serum, results in a diminution or disappearance of the opsonic effect. The number of pneumococci observed in some alveoli in Figure 11 would appear to be much in excess of that found to be appropriate for demonstrating the optimum opsonic effect of dog's serum in vitro. A certain interval of time is also necessary for the full action of the serum. During this period the pneumococci in the edema (opsonizing fluid) are increasing in numbers. A second time factor is introduced by the interval required for the arrival of leukocytes in the alveolar spaces. It seems likely, both from a theoretical viewpoint and from the picture shown in Figure 12 that the first leukocytes to arrive do not find all the pneumococci adequately prepared for phagocytosis since engulfment is not very active at this stage. Later when the polymorphonuclear leukocytes have arrived in large numbers, with presumably more opsonizing fluid, the pneumococci are found almost entirely within the phagocyting cells (Fig. 13). Meanwhile this cycle is being repeated at the periphery of the lesion. Whether the much diminished number of pneumococci, observed in the intensely consolidated area, is due entirely to phagocytosis and intracellular digestion we do not know.

The constant presence of pneumococci in the vessels of the parenchyma, observed early in the evolution of the lesion of experimental lobar pneumonia, would account for the frequent finding of bacteremia at the beginning of the disease. Considering the degree of intravascular invasion it is surprising that pneumococci were not recovered from the blood stream in every instance. In a series of observations on dogs, infected with small doses of pneumococci and allowed to survive (not included in Table I), blood cultures, taken at short intervals during the first few hours of the disease, were mostly negative. However, a dog showing an early positive culture might show successive negative cultures or vice versa. The number of bacteria recovered was usually 1 to 5 per cc. of blood. These findings together with the histological picture would suggest that there is probably a constant escape of pneumococci from the lungs in the early phases of the disease, and that the irregularity with which they are detected by blood culture is due to their effective removal by the phagocytic cells of the reticulo-endothelial system in the regional lymph nodes, liver, spleen, etc.

\section{SUMMARY}

In order to study the evolution of the lesion of experimental pneumococcus lobar pneumonia in the dog, a series of animals were killed at intervals of one to twenty-four hours following the initiation of the infection. Within one hour after implanting pneumococci suspended in a starch broth medium into a terminal bronchus, a definite local inflam- 
matory reaction had occurred. This consisted of a central area of cellular infiltration, hemorrhagic and exudative in character, surrounded by a zone of alveoli filled with edema fluid in some parts, and starch in others, and accompanied by engorgement of the blood vessels, the larger of which showed perivascular edema. With the lapse of time the lesion showed progressive growth, extending radially from the initial focus. This process was characterized by an advancing zone of edema-filled alveoli which in turn were gradually invaded by polymorphonuclear leukocytes and red blood cells until they were filled and distended by the exuded cells. Inflammation of the interalveolar septa was an inconspicuous feature although peribronchial and perivascular edema was marked. The pathological lesion was at first definitely lobular or circumbronchial in distribution but after a few hours lost its association with the bronchi and became a continuous area principally of intra-alveolar cellular exudate. By the end of six to twelve hours the oldest portion of the lesion began to suggest the mosaic appearance of the human lung in lobar pneumonia. Within twenty-four hours, usually, a whole lobe was consolidated and, at times, spreads to other lobes had occurred.

Dispersion of the pneumococci within the first few hours appeared to take place principally through the lung parenchyma since these bacteria were observed in considerable numbers in the walls of alveoli which appeared normal and lay beyond the margin of the zone of edema. Later in the process the character of their distribution suggested that the pneumococci were also carried by the edema fluid through the smaller air passages. Marked regional differences in the distribution of the microorganisms were observed. At the periphery of the lesion the pneumococci were present in great numbers lying free in the edema-filled alveoli. In the immediate underlying zone of cellular exudate they were fewer in number, and lay partly within the polymorphonuclear leukocytes, while in the oldest part of the lesion, showing intense cellular infiltration, relatively few pneumococci were seen, and these were practically entirely intracellular. On the basis of these observations certain inferences were drawn concerning the propagation of pneumococcus infection in the lung of the $\mathrm{dog}$.

\section{BIBLIOGRAPHY}

(1) Robertson, O. H., Coggeshall, L. T., and Terrell, E. E., J. Clin. Invest., 1933, xii, 433. Experimental Pneumococcus Lobar Pneumonia in the Dog. II. Pathology.

(2) Terrell, E. E., Robertson, O. H., and Coggeshall, L. T., J. Clin. Invest., 1933, xii, 393. Experimental Pneumococcus Lobar Pneumonia in the Dog. I. Method of Production and Course of the Disease.

(3) Coryllos, P. N., and Birnbaum, G. L., Arch. Surg., 1929, xviii, 190. Lobar Pneumonia Considered as Pneumococcic Lobar Atelectasis of the Lung: Bronchoscopic Investigation. 
(4) Henderson, Y., Haggard, H. W., Coryllos, P. N., and Birnbaum, G. L., Arch. Int. Med., 1930, xly, 72. The Treatment of Pneumonia by Inhalation of Carbon Dioxide. I. The Relief of Atelectasis.

(5) Van Allen, C. M., and Wu, C., J. Clin. Invest., 1932, xi, 589. Increased Elastic Tension of the I.ung in Experimental Pneumonia.

(6) Miller, William Snow, Am. Rev. Tuberc., 1919-1920, iii, 65. Studies on Tuberculous Infection. II. A Description of Plastic Models (Reconstructions) of a Conglomerate Tubercle and the Surrounding Structures in a Human Lung.

(7) Loeschcke, H., Beit. z. path. Anat. u. z. allg. Path., 1931, lxxxvi, 201. Untersuchungen über die kruppöse Pneumonie.

(8) Permar, H. H., J. Med. Research, 1923, xliv, 1. The Pathogenesis of Experimental Pneumonia in the Rabbit.

(9) Rhoads, C. P., and Goodner, K., J. Exper. Med., 1931, liv, 41. The Pathology of Experimental Dermal Pneumococcus Infection in the Rabbit.

(10) Blake, F. G., and Cecil, R. L., J. Exper. Med., 1920, xxxi, 445. Studies on Experimental Pneumonia. II. Pathology and Pathogenesis of Pneumococcus Lobar Pneumonia in Monkeys.

(11) Robertson, O. H., and Sia, R. H. P., J. Exper. Med., 1927, xlvi, 239. Studies on Pneumococcus Growth Inhibition. VII. The Relation of Opsonins to Natural Resistance against Pneumococcus Infection. 